\title{
In situ W-NiTi shape memory alloy composite of high radiopacity
}

\author{
S. Wang ${ }^{\mathrm{a}}$, F. M. Guo ${ }^{\mathrm{a}}$, D. Q. Jiang ${ }^{\mathrm{a}}$, Y. Liu ${ }^{\mathrm{b}}$ and L. S. Cuia ${ }^{\mathrm{a}}{ }^{*}$ \\ ${ }^{a}$ Department of Materials Science and Engineering, China University of Petroleum-Beijing, Beijing, \\ Changping 102249, China \\ ${ }^{b}$ School of Mechanical and Chemical Engineering, The University of Western Australia, Crawley, WA \\ 6009, Australia \\ *Corresponding author. Tel.: +86 10 89731158; fax:+86 10 89731158; e-mail: \\ lishancui63@126.com
}

\begin{abstract}
An in-situ NiTi-11 at.\% W shape memory alloy composite was fabricated via two-step melting: first melting a prefabricated powder-sintered Ni-20 at.\% W block and then adding titanium into the melt. After solidification, a W-NiTi composite ingot was obtained with in-situ formed tungsten particles uniformly dispersed in the NiTi matrix. The composite ingot was drawn into wire composite of NiTi matrix and $\mathrm{W}$ fibers. The composite wire exhibits reversible martensitic transformation, superelasticity and improved radiopacity due to the presence of tungsten.
\end{abstract}

Keywords: shape memory alloys; composites; melting; microstructure; tungsten

NiTi shape memory alloys (SMAs) have been widely used in biomedical applications [1-4], such as catheters, stents and guide wires due to their good biocompatibility [4-7] and unique mechanical properties associated with the reversible martensitic transformation [8]. A significant disadvantage of NiTi SMAs in such applications is their insufficient radiopacity $[4,9,10]$, which is inconvenient for cardiologists or physicians to estimate the 3D position and orientation of a component or a device inside the body using radiographic technique. With the progress of miniaturization of medical devices and development of minimum invasive surgery, this shortfall has become a major obstacle in their application [11]. To overcome this, techniques such as coating with a surface layer [12, 13] or adding a mark made of gold, platinum or tantalum [4,9] have been used to enhance their radiopacity, while complications including material compatibility, biocompatibility, coating adhesion, high cost also arise. Tungsten has a high radiopacity, good biocompatibility $[14,15]$ and relatively low price, which make it a good candidate for improving the radiopacity of NiTi SMAs for medical applications. In this area, efforts have been made by using laser surface cladding [16] and hot isostatic pressing (HIP) sintering [17] to add tungsten into NiTi. However, laser-clad NiTi with tungsten powder showed decreased strength and elongation, largely due to thermal damage to the NiTi caused by the process. The NiTi/W composite fabricated by HIP sintering of NiTi-9 at.\% W powder mix exhibited poor deformability as the tungsten particles were only weakly bonded to the NiTi matrix. These drawbacks severely hinder the further development of the materials and their applications. In this work, we adopted a different approach by designing and fabricating an in situ NiTi-11 at.\% W matrix-particle intermetallic 
composite via alloy solidification. This technique allows large quantity production, true intermetallic interface bonding and uniform dispersion of $\mathrm{W}$ phases in the NiTi matrix.

A W-NiTi composite ingot of $\sim 7 \mathrm{~kg}$ was fabricated by means of vacuum induction melting in a $\mathrm{CaO}$ crucible. The ingot has a nominal mixing composition of 45 at.\% $\mathrm{Ti}, 44$ at.\% $\mathrm{Ni}$ and 11 at.\% W. To facilitate the addition of tungsten, a commercial Ni-20 at.\% W prefabricated block supplied by Beijing Tian-Long Tungsten \& Molybdenum Co., Ltd. was used in this study. The block was prepared first by powder mixing, cold isostatic pressing and sintering. Tungsten has a melting point of $\sim 3400{ }^{\circ} \mathrm{C}$ and thus cannot be directly melted with NiTi, but can be dissolved in molten $\mathrm{Ni}$ at a relatively low temperature (please refer to the $\mathrm{Ni}-\mathrm{W}$ phase diagram [18]). The pre-sintered block allows adequate contact between $\mathrm{W}$ powder and the $\mathrm{Ni}$ matrix for interfusion, and at the same time protects $\mathrm{W}$ powder from excessive oxidation during melting. The sintered block was then melted at $\sim 1600^{\circ} \mathrm{C}$, during which $\mathrm{W}$ dissolves into molten $\mathrm{Ni}$ to form the molten alloy. Titanium blocks were added into the Ni-W melt and then the alloy melt was allowed to solidify into the final W-NiTi composite ingot. The ingot was free forged at $850^{\circ} \mathrm{C}$ into a bar of $16 \mathrm{~mm}$ in diameter and swaged at $850^{\circ} \mathrm{C}$ into a bar of 8 $\mathrm{mm}$ in diameter. The bar was then hot drawn into thin wires with diameters of 0.65 and $1 \mathrm{~mm}$ at $750{ }^{\circ} \mathrm{C}$, and cold drawn into thin wires of 0.5 and $0.74 \mathrm{~mm}$ in diameter with $>40 \%$ cold deformation in elongation.

The structure of the composite ingot was characterized by X-ray diffraction (XRD) analysis using a Bruker AXS D8 Advance diffractometer with $\mathrm{Cu} \mathrm{K \alpha}$ radiation $(\lambda=1.5418 \AA$ ). Microstructure observations and composition analysis were conducted using a FEI Quanta $200 \mathrm{~F}$ scanning electron microscope operated at $20 \mathrm{kV}$ in combination with an X-ray energy-dispersive spectroscopy (EDS) analyzer. Phase transformation behavior was analyzed by means of differential scanning calorimetry (DSC) using a Netzsch DSC 204 F1 Phoenix unit with a heating/cooling rate of $10^{\circ} \mathrm{C} / \mathrm{min}$. Tensile tests were conducted on a WDT II-20 testing machine with a strain rate of $1 \times 10^{-4} \mathrm{~s}^{-1}$. High-energy X-ray absorption coefficient was calculated based on the composition, density and the mass attenuation coefficient data of the constituent elements for $100 \mathrm{keV}$ photons obtained from the NIST Standard Reference Database. Radiopacity of the composite wires was measured by means of X-ray photographic method using a dental X-ray unit (Sirona HEILODENT PLUS D3507 Germany) with an x-ray tube power of $60 \mathrm{~kW}$, a current of $7 \mathrm{~mA}$ and an exposure time of 0.25 second.

Figure 1 shows the microstructural analysis of the in situ W-NiTi composite. Figure 1(a) is a back scattered scanning electron micrograph (BSEM) of the sintered Ni-W block. It is seen that it contains $\mathrm{W}$ particles with a mean size of $\sim 30 \mu \mathrm{m}$ well dispersed in the Ni matrix. EDS analysis confirms that the Ni matrix contains $\sim 15$ at.\% W while the tungsten particles are practically pure. It is also evident that the $\mathrm{W}$ particles are rugged and irregular in shape, implying that they are still the original powder particles. Figure 1(b) shows an XRD spectrum of the $\mathrm{W}$-NiTi composite ingot at room temperature. The diffraction peaks are indexed to tungsten, B19'-NiTi and B2-NiTi. Figure 1(c) shows a BSEM of the microstructure of the W-NiTi composite ingot. The ingot consists of well dispersed tungsten particles in the NiTi matrix. It is obvious that the W particles, with a mean size of $\sim 10 \mu \mathrm{m}$, 
are much smaller than those in the sintered Ni-W block and the shapes are rounded and smooth, implying that these $\mathrm{W}$ particles have been reformed from the melt instead of being the original in the powder. EDS analysis confirms that the $\mathrm{W}$ particles contain no $\mathrm{Ni}$ or $\mathrm{Ti}$. This implies that, in the first melting step, $\mathrm{W}$ is dissolved in molten nickel (as per the Ni-W phase diagram [18]), and that after titanium addition, the nickel in Ni-W melt reacts with titanium to form NiTi whilst tungsten precipitates out as small particles. A W-NiTi particle-matrix in situ composite thus forms after solidification.
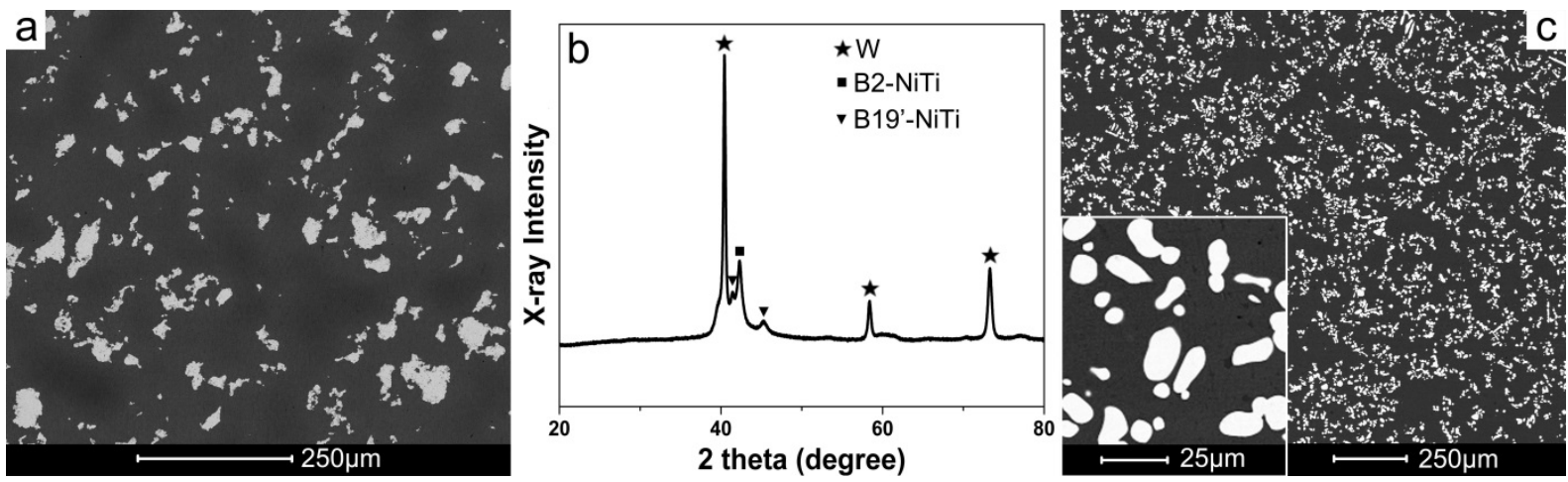

Figure 1. Microscopic analysis of the in situ W-NiTi composite. (a) Backscattered scanning electron micrograph (BSEM) of the sintered Ni-W block. (b) XRD spectrum of the W-NiTi composite ingot. (c) BSEM of the W-NiTi composite ingot (inset: higher magnification view). The bright regions are $\mathrm{W}$ particles and the dark region is the NiTi matrix.

Figure 2 shows the in situ W-NiTi composite wire with a diameter of $0.74 \mathrm{~mm}$. Figure 2(a) shows the wire produced. It is evident that the in situ W-NiTi composite has excellent deformability and processibility. Figure 2(b) and 2(c) show the microstructure along the length and the cross-section of the wire, respectively. As can be seen, after wire drawing, the tungsten particles have been converted into micron-scale ribbon-like fibers well dispersed in the NiTi matrix and aligned along the wire axial direction. The mean width of the tungsten fibers is $\sim 0.8 \mu \mathrm{m}$.

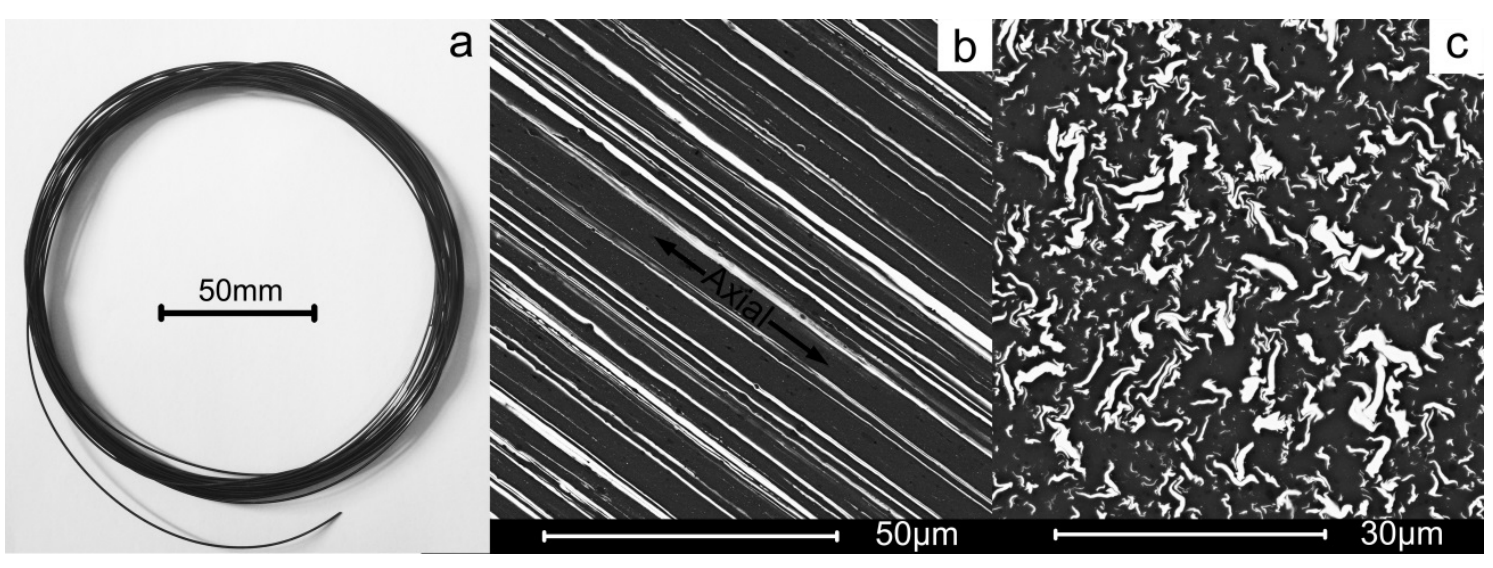


Figure 2. In situ W-NiTi composite wire. (a) A coil of the composite wire. (b) and (c) BSEM of the longitudinal-section and cross-section of the composite wire (bright regions are $\mathrm{W}$ fibers; dark region is the NiTi matrix).

Figure 3 shows the phase transformation behavior and mechanical properties of the in situ W-NiTi composite wire with a diameter of $0.74 \mathrm{~mm}$. Figure 3(a) shows DSC measurements of the as-drawn and annealed composite wire samples. The as-drawn wire (sample (a)) shows one broad exothermic peak centered at $335{ }^{\circ} \mathrm{C}$ on heating, apparently associated with the crystallization of the amorphous NiTi phase caused by the cold-drawing [19]. Sample (b) was annealed at $350{ }^{\circ} \mathrm{C}$ for 20 minutes. This sample exhibits a typical single-step $\mathrm{B} 2 \leftrightarrow \mathrm{R}$ transformation at $48{ }^{\circ} \mathrm{C}$ during cooling and $54{ }^{\circ} \mathrm{C}$ during heating, as indicated by the two peaks with small hysteresis of $\sim 6{ }^{\circ} \mathrm{C}$ and small transformation enthalpy change of $\sim 2 \mathrm{~J} / \mathrm{g}$ [8, 20]. Sample (c) was annealed at $600{ }^{\circ} \mathrm{C}$ for 20 minutes. This sample exhibits a B2 $\rightarrow \mathrm{R} \rightarrow \mathrm{B} 19^{\text {' }}$ two-stage martensitic transformation on cooling and a B19' $\rightarrow$ B2 transformation on heating.
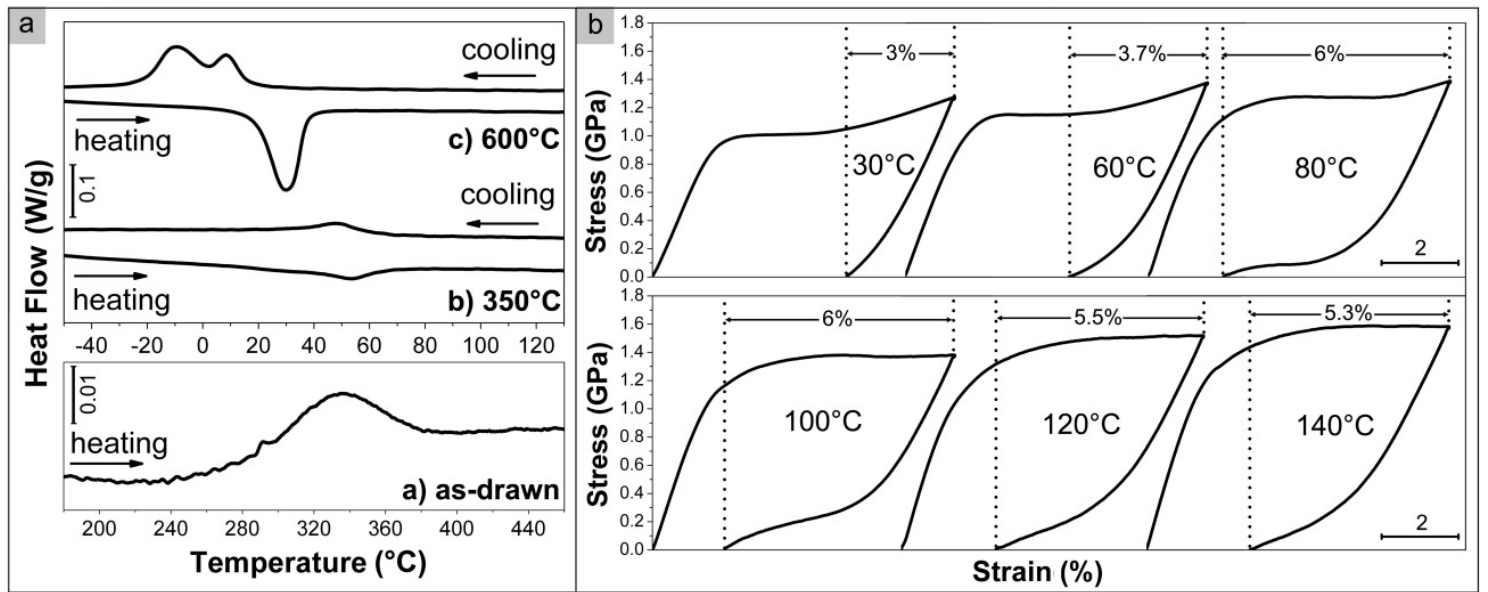

Figure 3. Phase transformation behavior and mechanical properties of the in situ W-NiTi composite wire. (a) DSC curves of the as-drawn W-NiTi composite wire and of wire samples annealed at $350{ }^{\circ} \mathrm{C}$ and $600{ }^{\circ} \mathrm{C}$ for 20 minutes. (b) Tensile stress-strain curves at various temperatures of the composite wire annealed at $350{ }^{\circ} \mathrm{C}$ for 20 minutes.

Figure 3(b) shows the tensile stress-strain curves at different temperatures of the in situ $\mathrm{W}$-NiTi composite wire annealed at $350{ }^{\circ} \mathrm{C}$ for 20 minutes. One can see that the composite wire does not exhibit superelasticity at $30{ }^{\circ} \mathrm{C}$. This is consistent with the DSC observation (Figure 3(a)), which shows that the NiTi matrix is basically R-phase at this temperature. As the testing temperature rises, the composite wire shows partial superelasticity at between $60{ }^{\circ} \mathrm{C}$ and $140{ }^{\circ} \mathrm{C}$. The recoverable strain of the composite wire increases first with increasing the tensile temperature from $60^{\circ} \mathrm{C}$ to $100^{\circ} \mathrm{C}$ and reaches up to $6 \%$, then decreases with increasing the tensile temperature from $100{ }^{\circ} \mathrm{C}$ to $140{ }^{\circ} \mathrm{C}$. The residual strain is caused by the plastic deformation of both the NiTi matrix and tungsten fibers. The plateau stress of the composite wire can be up to $1.6 \mathrm{GPa}$, which may result from both the strengthening effect 
of the tungsten fibers and ultrafine grain structure of the NiTi matrix produced by the low-temperature anneal $\left(350^{\circ} \mathrm{C}\right)$ (Figure 3(a)).

Figure 4 shows a comparison of X-ray radiopacity for the in situ W-NiTi composite wire and a commercial Ti-50 at.\% Ni alloy wire. The inset shows X-ray photographs of the two samples, each consists of several wires $(0.5 \mathrm{~mm}$ in diameter) arranged in parallel together on a thin plastic foil substrate. It is evident that the W-NiTi composite shows a much brighter and clearer X-ray image as compared to the NiTi wires. The chart shows the X-ray absorption coefficients of the two materials, as calculated based on alloy composition. It is seen that the $\mathrm{X}$-ray absorption coefficient of the in situ W-NiTi composite is more than 5 times of that of NiTi. Considering the significant contribution of $\mathrm{W}$ to radiopacity, for property optimization, it may be suggested that appropriate reduction of the $\mathrm{W}$ content may be applied in order to preserve the shape memory properties of NiTi whilst maintaining adequate radiopacity for intended applications.

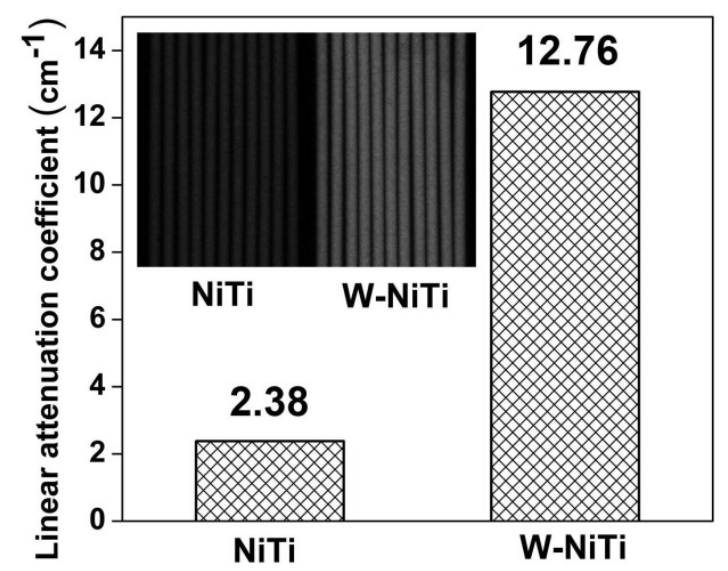

Figure 4. Comparison of X-ray radiopacity between the W-NiTi composite and a Ti-50 at.\% Ni alloy by calculated linear attenuation coefficient for $100 \mathrm{keV}$ X-ray and X-ray photographs (inset).

In this work we fabricated an in situ W-NiTi composite ingot containing 11 at.\% W in uniformly-dispersed particles with well-bonded interfaces with the matrix. The composite ingot possesses good deformability and can be easily drawn into wire form with tungsten fibers well dispersed in the NiTi matrix and aligned along the wire axial direction. The composite wire exhibit much increased strength and partial superelasticity with a recoverable strain up to $6 \%$. The X-ray radiopacity of the composite is much higher than NiTi. This work lays the foundation for the future design of high radiopacity in situ W-NiTi composites for biomedical applications.

\section{Acknowledgements}

This work was supported by the key program project of National Natural Science Foundation of China (NSFC) (51231008), the National 973 programs of China (2012CB619403), the Australian Research Council (DP140103805) and the Key Project of Chinese Ministry of Education (313055). 


\section{References}

[1] T. Duerig, A. Pelton, D. Stöckel, Mat. Sci. Eng. A 273-275 (1999) 149.

[2] L.G. Machado, M.A. Savi, Braz. J. Med. Biol. Res. 36 (2003) 683.

[3] N.B. Morgan. Mat. Sci. Eng. A 378 (2004) 16.

[4] D. Stöckel, A. Pelton, T. Duerig: Eur. Radiol. 14 (2004) 292.

[5] S.A. Shabalovskaya, Bio-Med. Mater. Eng. 6 (1996) 267.

[6] S.A. Shabalovskaya, Bio-Med. Mater. Eng. 12 (2002) 69.

[7] C.L. Chu, R.M. Wang, T. Hu, L.H. Yin, Y.P. Pu, P.H. Lin, S.L. Wu, C.Y. Chung, K.W.K. Yeung, Paul K. Chu, Mat. Sci. Eng. C 28 (2008) 1430.

[8] K. Otsuka, X. Ren, Prog. Mater. Sci. 50 (2005) 511.

[9] D. Stöckel, C. Bonsignore, S. Duda, Min. Invas. Ther. \& Allied Technol. 11 (2002) 137.

[10] T.W. Duerig, M. Wholey, Min. Invas. Ther. \& Allied Technol. 11 (2002) 173.

[11] A. Kastrati, J. Mehili, J. Dirschinger, F. Dotzer, H. Schühlen, F. Neumann, M. Fleckenstein, C. Pfafferott, M. Seyfarth, A. Schömig, Circulation 103 (2001) 2816.

[12] R. Steegmueller, C. Wagner, T. Fleckenstein, A. Schuessler, Mater. Sci. Forum 394 (2002) 161.

[13] Y. Cheng, W. Cai, H.T. Li, Y.F. Zheng, J. Mater. Sci. 41 (2006) 4961.

[14] M. Peuster, C. Fink, P. Wohlsein, M. Bruegmann, A. G.unther, V. Kaese, M. Niemeyer, H. Haferkamp, C. Schnakenburg, Biomaterials 24 (2003) 393.

[15] M. Peuster, C. Fink, C.V. Schnakenburg, Biomaterials 24 (2003) 4057.

[16] X.J. Yan, H. Gugel, S. Huth, W. Theisen, Mater. Lett. 65 (2011) 2934.

[17] M. Bitzer, M. Bram, H.P. Buchkremer, D. Stöver, J. Mater. Eng. Perform 21 (2012) 2535.

[18] S.V. Nagender Naidu, A.M. Sriramamurthy, P. Rama Rao, J. Alloy Phase Diagrams 2 (1986) 1.

[19] K. Tsuchiya, Y. Hada, T. Koyano, K. Nakajima, M. Ohnuma, T. Koike, Y. Todaka, M. Umemoto, Scripta Mater. 60 (2009) 749.

[20] Y. Liu, J. I. Kim, S. Miyazaki, Philos. Mag. 84 (2004) 2083. 